This is an author produced version of a paper published in Climate and Development.

This paper has been peer-reviewed and is proof-corrected, but does not include the journal pagination.

Citation for the published paper:

Beckman, Malin; Nguyen, My Van Thi. (2016) Upland development, climate-related risk and institutional conditions for adaptation in Vietnam. Climate and Development. Volume: 8, Number: 5, pp 413-422. http://dx.doi.org/10.1080/17565529.2015.1067178.

Access to the published version may require journal subscription. Published with permission from: Taylor \& Francis.

Epsilon Open Archive http://epsilon.slu.se 


\title{
The Republican Zoopolis: Towards a New Legitimation Framework for Relational Animal Ethics
}

Erica von Essen - erica.von.essen@slu.se

Swedish University of Agricultural Sciences

Ulls väg $28 \mathrm{~B}$

Box 7012

75007 Uppsala

Phone: 46-18671989

Michael Allen - allenmp@etsu.edu

East Tennessee State University

Box 70656

Johnson City, TN 37614-0651

Phone: 423-439-6625

\begin{abstract}
In this article, we develop a republican framework for relational animal ethics, recently popularized in Donaldson and Kymlicka's Zoopolis. This republican framework departs from the focus on negative rights that dominate liberal animal rights theories, especially as concerns our relations to wild animals. Our proposed framework appeals to a republican standard of non-arbitrariness, or non-domination, for human interferences with such animals. This legitimation framework is more attentive to relations of care and of dependency between the species, which we contend fits the growing field of relational animal ethics. At the same time, it requires rigorous criteria be met to legitimate relations as non-dominating. We apply this framework to the morality of the supplementary feeding of wildlife, using a case study of wild boars as fed by hunters. Weakening of the concept of domination to fit the predicament of boars, we show how the republican framework can provide a principled justification for legitimate interference with a wild animal population.
\end{abstract}




\section{Introduction}

An alternative to the negative rights slant in animal rights, focusing on abolition and hands-off approaches, has now surfaced within critical animal studies (Mackenzie and Natalie 2000; Friedman 2008). Indeed, Relational Animal Rights Theory (henceforth RART) lays a foundation for positive relations of care, mutuality and dependence between species. In so doing, the theory is sensitive to the multitude of ways in which human and non-human animals interact across shared territories. Perhaps the most fruitful development with RART is offered by Donaldson and Kymlicka (2011), insofar as it extends a positive relation also to wild animals. They present a tripartite framework for moral obligations toward non-human animals based on our relation to them in the political community. Here domestic, liminal and wild animals are cocitizens, denizens and sovereigns respectively. This tripartite framework defines our moral obligations towards non-humans and their corresponding political rights.

In this article, we argue Donaldson and Kymlicka's framework is compelling insofar as it stipulates positive duties in a field that has been dominated by negative rights (Rogers and Kaplan 2004). But we also believe that their proposed integration of negative rights and positive duties intuitively points in the direction of republican political theory rather than the liberal vein in which they write. Indeed, republicanism proposes this same integration of negative rights and positive duties, while arguing for a relational conception of justice as freedom from domination by others (Pettit 1996). We aim to develop an animal rights connection to republicanism and non-

domination within the context of the RART envisioned by Donaldson and Kymlicka. But we also believe, in accordance with several other critics (Cochrane 2013; Horta 2013; Hinchcliffe 2015; Ladwig 2015), that Donaldson and Kymlicka have been insufficiently attentive to problems of applying key political concepts in this context of human and non-human relations, such as sovereignty and representation. 
Indeed, the problems here are closely interrelated: sovereigns can be represented to the extent that they can accept or reject others as their representatives. In republican language, representations of sovereigns are legitimate only to the extent they can be effectively contested by those represented. Needless to say, effective contestation is out of bounds for wild animals, who lack the cognitive and communicative capacities requisite for legitimate relations of contestable representation between humans and non-humans (Eckersley 1999; Smith 2012). Contesting on behalf of non-communicative others to secure their freedom from domination does, however, currently takes place for the marginal cases of humans such as the cognitively disabled and some elders (Silvers and Francis 2005). This is provided those claims made resonate with others (i.e. they are not conjured out of the air) and are contestable by communicatively competent agents (Saward 2006). We believe, then, that there are contestable and therefore legitimate ways in which humans may represent non-humans, including wild animals.

The feeding of wild animals provides a case study of human interference for our philosophical argument. We analyze the sustained supplementary feeding of wild boars (Sus scrofa) by hunters in light of a republican standard of justification as non-dominating interference (Pettit 1997). Does feeding practice satisfy the standard for interference in a wild animal community with which humans are interrelated? In the case of supplementary feeding that we focus on, the practice is typically done to facilitate the hunting and killing of boars for sport and culling their high numbers (Geisser and Reyer 2004). This lack of a benign intent behind the interference, indeed a kind of deception and a violation of the duty of fidelity in the language of Taylor (1992), suggests a prima facie case for saying supplemental feeding of wild boars constitutes a relation of domination. Nonetheless, we ask in accordance with republican criteria: (1) whether or to what extent it might satisfy the republican standard of non-dominating interference by respecting the good of the wild boar community; and (2) whether the practice of 
feeding is checked by appropriate accountability mechanisms preventing it from lapsing into unjustifiable, dominating interference in this wild animal community.

Our line of argumentation requires us to reinterpret the concept of domination in order to take into account that boars do not, as Donaldson and Kynlicka would argue, constitute a sovereign community as characterized by moral powers of self-determination (Cochrane 2013). This leads us to develop an idea of agentless domination (Lovett 2010): the domination of those who cannot conceptualize or communicate their good or contest different and opposing judgments as to how it is best understood in a given context of dispute. With respect to the contestability of the human/non-human relation, we develop the idea of proxy or dependent representative claim-making on behalf of wild animals. Donaldson and Kymlicka endorse this model for co-citizens, but fail to extend it to wild animals (Cochrane 2013). Proxy representation is a political process in which human disputants discursively construct the good of the wild boars in different contestable ways (Saward 2006). Here, we argue that determining whether public decisions regarding the continuation, stopping, or regulation of feeding for the boars satisfy the standard of non-arbitrary interference will be a function of robust critical deliberative processes of claim-making.

Determining the moral status of supplementary feeding of wild game is urgent not least from a republican-based RART perspective. But its legitimacy is also inseparable from the legitimacy of hunting in contemporary society. While public acceptance of hunting is very high at 86 percent in Sweden (Gadolin 2014) when compared to continental European states and North America (Peterson 2004), the supplementary feeding of wild boars raises ethical concerns over the extent of our stewardship. Practices that confuse political relations in the shared interspecies community, or Zoopolis, may risk eroding the public perception of both hunters and wild boars. 
This paper is divided into four sections. First, we describe the feeding issue in Sweden.

Second, we determine the political status of wild boars and engage with hunters' defences of feeding as affirming natural relations between the species. Third, we frame the feeding issue within the republican framework to determine its legitimacy. Fourth and finally, we tackle some key objections to framing the issue in republican terms. We situate our discussion within emerging scholarship within Relational Animal Rights Theory (RART), pioneered by Midgley (1983) and taken further by Burgess-Jackson (1998), Scruton (2000), Palmer (2012) and not least Donaldson and Kymlicka (2011), whom we credit for providing our point of departure. Our republican slant to animal rights provides a forward-looking framework that might challenge the liberal preoccupation with negative duties currently stifling the field (Clement 2003; Horta 2013). Our discussion is intended not just as a contribution to RART and to the 'political turn' in animal rights, but also as a call to wildlife managers and hunters to reassess the legitimacy of supplemental feeding practices.

\section{The feeding issue}

Supplementary feeding refers to the provision of natural or artificial feed, commonly grain, fruit or vegetables but in some cases animalist by-products or processed foods to wild animals (Dunkley and Cattet 2003). Feeding can be on a supplementary, emergency, winter or intercept nature, where the latter refers to feeding as a diversionary tactic that leads wildlife away from crops or human settlements (Dunkley and Cattet, 2003; Geisser and Reyer 2004). The most valued and common form of supplementary feeding among Swedish hunters is that of roe deer in the winter months. Among members of the public, by contrast, bird-feeding is extensive and not generally regarded as an interference in the wild, reflected in its scale and ubiquity across the western world (Jones and Reynolds 2008). 
Supplementary feeding is substantially less regulated in Sweden than in other parts of Europe where more detailed restrictions apply. This paucity of regulation can be attributed to the proviso 'freedom with responsibility' that characterises Swedish hunting. As part of the 2014 review of the hunting law, which comprises feeding regulation, a prohibition of supplementary feeding of wildlife is proposed during non-winter months. Even during other seasons, the new legislation seems to indicate it will be easier to impose local prohibitions on feeding from the County Administrative Board, unless satisfactory agreements can be reached between landowners and hunters.

Of all the fed wild species, wild boars are rapidly proliferating in Southern and Middle Sweden (Lemel and Truve 1999). This is attributed to a combination of boars having only humans as predators, being notoriously difficult to shoot, rejuvenating multiple times per year, and suffering no negative consequences of density dependency, while enjoying extensive supplementary feeding of all sorts of foods (Leaper, Massei, Gorman and Aspinall 1999; Bieber and Ruf 2005; Borowik, Curnlier and Jędrzejewska 2013). The population explosion of boars is reflected across the European continent where they are now the second most abundant ungulate and the most rapidly multiplying species (Keuling, Stier and Mechtild 2009; Apollonio, Andersen, Reidar and Putman, 2010; Ucarli 20111). This is globally paralleled by feral pigs in Australia, invasive swine in the US, and crop-raiding warthogs in parts of Africa (Hampton, Spencer, Alpers, Twigg, Woolnough,Doust, Higgs and Pluske, 2014; Littin and Mellor 2005; Massei, Coats, Quy, Storer and Cowan 2010; Parkes, Ramsey, Macdonald, Walker, McKnight, Cohen and Morrison 2010).

The damage done to agricultural crops by boar tusks when feeding, raising piglets or using cropland as shelter, is reportedly extensively (Geisser and Reyer 2004; Herrero, GarcíaSerrano, Couto, Ortuño, and García-González 2006; Ucarli, 2011). Farmers object to feeding as 
boars overpopulate rural areas and destroy crops. Ecologists by and large caution against such a degree of human interference with feeding patterns of wildlife. Indeed, the cascade effects of their proliferation and simultaneous dependency on human intervention are either uncertain or may wreak ecological havoc (Brittingham and Temple 1992; Fischer; Stallknecht, Luttrell, Page; Dhondt and Converse 1997; Dunkley and Cattet 2003; Jones, 2011)

Hunters, on the other hand, are generally pro supplementary feeding and go to great lengths to provide for their game. Their rationale is that it facilitates hunting the boars by concentrating the distribution of game to feeding stations (Geisser and Reyer 2004). Hunters also claim supplementary feeding minimizes the suffering that would face many starving boars in the winter. This satisfies their conscience, knowing that wild animals survive the winter months. All in all, the arguments of hunters have engendered a vexed socio-political situation wherein supplementary feeding of a thriving, partly invasive population has become a frequent source of conflict between hunters and farmers sharing the countryside.

\subsection{The political status of wild boars}

Donaldson AND Kymlicka's (2011) argument is that the duties owed to wild boars are a function of our position in relation to them in the political community. Animals are 'domestic,' 'liminal,' or 'wild' which are tantamount to 'citizen,' 'denizen,' and 'sovereign' respectively. Our duties toward sovereigns involve protecting their autonomy without exploitative or paternalistic outside interference. It requires that we recognize that wild animals have the inclination, the capacity and, above all, the right to form autonomous sustaining communities. That is not to say we cannot or should not offer aid and assistance or, in extreme cases, intervention-especially if we are somehow causally responsible for their predicament. To clarify this, Donaldson and Kymlicka (2011) distinguish between legitimate and illegitimate intervention, where the former restores the 
realization of the species' sovereignty, while the latter creates dependency. In their argument, intentionally creating dependency on humans is what is unjustifiable. This is in contrast to Taylor's (1992) interpretation. Feeding wild animals and culling them at these sites would clearly violate both the duty of non-interference with wild animals and the duty of fidelity, meaning not to deceive wild animals.

For all intents and purposes, wild boars begin as sovereigns in Donaldson and Kymlicka's framework, who shun interaction with humans. Respecting this, humans have previously honoured their "natural competence" and capacity for survival (Regan 1983) by not interfering in their predation, feeding or breeding cycles. Although having started from a position as sovereigns, we contend boars have now moved increasingly toward denizenship. This follows from their dependency on human-provided foods and their resultant routine transgression on human settlements. In this way, their denizenship is partly something we have caused, but also a natural result of their dispersal following increased populations. As denizens who interact or make use of human resources, their crop raiding behaviour have inscribed them with labels of pests and parasites, and they are termed 'pig devils' in some parts of Southern Sweden (Johansson 2005). An important corollary of their moving toward denizenship is that boars are becoming subjects in regards to whom it is thought justifiable to suspend our moral obligations. This much is often the case for varmint (Lukasik and Alexander 2011). In this regard they are paralleled by the status of undocumented immigrants or a rabble population — they are neither owed the duties commanded by pets as co-citizens, nor the respect for autonomy owed to sovereign wildlife.

Nonetheless, hunters defend supplementary feeding by first purporting that the size of wildlife populations are best regulated through hunting at this point and not through starvation. Culling at feeding stations is presented as the most efficient and humane way of dealing with the 
boars. To be sure, hunters who practice supplementary feeding of wild boars kill three times as many boars as those who do not (Dunkley and Cattet 2003; Geisser and Reyer 2004). This higher kill-ratio reflects an interesting fault line between bird feeding and game feeding. Where the former is linked to promoting values of conservation (Green and Higginbottom 2000), the latter appears to cultivate a stronger predation ethic (Dunkley and Cattet 2003).

The hunters that defend the management of wild boars through feeding and culling as the more humane alternative join a prominent utilitarian narrative within hunting ethics. Namely, that it is less painful for an animal to die from a swift gunshot by a skilled hunter than it is from disease, starvation, or natural predation in the wild (Loftin 1984; Everett 2001; Svendsen Bjørkdahl 2005; Cahoone 2009). Hunters are consequently presumed ethical by intervening to remedy nature's 'grisly drama' (Sagoff 1984; Hettinger 1994; Samuel 1999). In Swedish, it is arguably significant that that the term for game management is the equivalent of 'wildlife care'. Critics of the duty-to-prevent-suffering argument, however, suggest hunters' self-representation as "Florence Nightingales with rifles" (Kerasote 1994) is a sanitization of something that is motivated by more esoteric drivers than doing what is best for the animals.

A second defence of supplementary feeding offered by hunters is to highlight the moral inconsistencies of feeding certain species and withholding this intervention from others. Here, they may contend bird-feeding is a sufficiently popular practice that it imparts virtue to providing for wild animals through harsh times. Or, they may argue that proliferation of the great tit (Parus major), a commonly fed wild species in the country, is not producing observable damage in the same way as do the wild boars. But, even if the tit's impact is not conspicuously nuisant to humans, it is obviously false to presume that proliferation has no such negative effects on other species; or indeed, the ecosystem of which they form a part (Brittingham and Temple 1988). 
Third, hunters might defend supplementary feeding by arguing for the intrinsic virtue of stewarding wild animals. Orams (2002) declares that the sharing of food with animals is a spiritual, reciprocal, and natural parenting response across human cultures. Feminist scholars in particular have embraced this refrain, critiquing the hands-off approaches advocated by the liberal, justice-based slant to animal rights (Noddings 1984; Curtin 1991; Clement 2003). Their views are substantiated by anthropologists who posit that the provision of small amounts of food to attract wildlife has in all likelihood featured in human settlements for millennia (Kellert 1997). It is only in recent decades that this feature of human settlement has become extensive, commercialized and linked to game management practices (Chinery 2004). It is easy to challenge this argument, however, as guilty of the naturalistic fallacy on two related fronts. To wit, neither historical precedence nor human biology can offer a cosmic sanction for a human cultural practice (Bateson 1989; Moriarty and Woods 1997).

Fourth and finally, hunters might appeal to biocentrist ethics by arguing that they value the well-being of individual animals with whom some sort of relation is established (as local residents or symbionts) above that of abstract cascade effects that may occur within the ecosystem, as a result of interference with food cycles. While a prima facie questionable justification, this is certainly the worldview taken by many bird-feeding members of the public. Those wild animals they can see outside their window take precedence over abstract contingencies and interspecies dynamics, such as the well-fed great tit out-competing other birds for nesting sites.

Indeed, the public might not approach any ecocentrist outlook until feeding wildlife becomes a large-scale, impersonal enterprise. At this point, morality shifts from 'playing angel' in prosaic small-scale interventions with proximate others to 'playing god' in systemic intervention (Henderson 2009). These arguments considered, we agree with scholars that one 
should be somewhat cautious about attributing kindness and sensitivity to hunters along the above lines of argumentation (Wood Jr. 1996; Luke 1997). Such kindness, after all, is difficult to reconcile with the principles that sanction killing.

\section{Appeals to non-domination - feeding in republican theory}

\subsection{The problem of sovereignty}

If we accept the originally sovereign status of wild boars, we make some tenuous assumptions that necessarily accompany the application of human political concepts to nonhuman animals. For one, it might be argued that in assigning them statuses of citizenship or sovereignty, we inadvertently bind them to certain obligations and standards that they have neither asked for nor have the capacity to fulfill (Scruton 2000). Second, and more importantly, we imply wild boars as sovereigns possess a meaningful concept of self-determination, in the sense of a "normatively defined authority structure existing within a community." (Wadiwel, 2013). But such a conception of sovereignty is difficult to discern in most animal cases. Indeed, in response to Zoopolis, scholars now seriously question the utility of applying the sovereignty concept to animals (Cochrane 2013; Horta 2013; Hinchcliffe 2015; Ladwig 2015). While some wild animals do possess authority structures that regulate important aspects of their lives, including predation, reproduction and migration (Palmer, 2012), the normative and conceptual implications of sovereignty requires a shared collective interest in self-determination. This is beyond even pack animals' social horizon of orientation (Ladwig 2015). In the case of wild boars, there are few, if any, abiding qualifying structures in their communities that we know of. ${ }^{\mathrm{i}}$

Donaldson and Kymlicka respond this concern by expanding the concept of sovereignty from beyond legal institutions, while having sovereignty fulfill the same function: a principled and pragmatic argument for preventing injustices against the wilderness (Donaldson and 
Kymlicka 2015). For them, sovereignty as understood in the animal case now merely entails 1) an independent existence, 2) upon which value is placed, 3) resistance to alien rule and 4) the possession of recognisable interests in their social organization. These criteria for sovereignty could reasonably apply to wild boars. Indeed, Donaldson and Kymlicka would likely contend by appeal to the ideas of MacKinnon (2005) that boars demonstrate their sovereignty not by collective self-determination, but by "voting with their feet;" or, in this case hooves, insofar as they shun human interference. But this seems to us, to divest sovereignty of its essential institutional political features. We therefore contend the wild boar population can be understood as qualifying as a community, but not a sovereign body. In this respect, the boar community is not dissimilar to the marginal cases of humans in terms of their lack of voice and lack of political autonomy (Eckersley 1999; Wong 2010).

If, like Horta (2013), we take community as a weakened form of sovereignty, and, like Hinchcliffe (2015), members as weakened forms of citizens, then by parity of reasoning what we should be concerned with is protecting the goods of its members and protecting them from domination, and not the elusive, political marker of sovereignty that does not meaningfully obtain for most animal cases. Indeed, sovereignty obscures interferences which are consistent with the ends of the community by appealing to a violation of a non-existent authority structure. To overcome this, we need a more appropriate theory of interference that admits of human obligations to legitimate the act.

\subsection{The solution of republicanism}

We began by noting that the political turn in animal rights, and indeed now even in RART, is characterised by a liberal framework that overwhelmingly works with negative freedoms. But we believe republicanism to be a better fit for the types of positive, relational 
rights and duties that arise in the shared interspecies community. Republicanism has enjoyed a revival in political philosophy that understands freedom as embracing collective membership, intersubjective reason and rights of contestation (Allen 2011; Benton 2011). It locates freedom not in the absence of interferences but in a state of non-domination, which is achieved insofar as the subject is free from arbitrary interference with his or her actions (Pettit 1996; Pettit 2001). To the extent that this is a perspective that can clarify the legitimacy of interferences with wild animals, the republican conception of freedom can be distinguished from the liberal negative freedom through the example of guards in wildlife parks dominating the animals under their supervision.

In this scenario, even if they are permitted to live their lives absent interference, the animals in the park remain utterly subject to the arbitrary will of the guard (Ladwig 2015). Indeed, by itself, the liberal criterion of non-interference offers no principled guidance as to whether or not interference by the guard is justified to secure an animal's good when this is jeopardized by any number of contingencies. In other words, it is insufficiently sensitive to tell us when there is something wrong with the negative stance of the guard, and why the latter should be bound by positive obligations of interference. To be sure, the guard may resort to ad hoc pragmatic or consequentialist reasons to act on behalf of the animals, but remains a dominator as long as these responses lack any well-defined principled justification. In this respect, republican theory demands that important criteria relating to the subject's good and the contestability of the relation are met. Moreover, these are criteria that cannot be subsumed under Donaldson and Kymlicka's appeal to the sovereignty of wild animals for reasons we shall further develop shortly, which concern the limited cognitive capacities of animals such as the boars.

The first criterion to freedom from domination may be attained if the interference is consistent with the good of the subject. To clarify, when countries provide emergency aid to other 
sovereign states in times of crisis interference is exercised towards those states as selfdetermining subjects (Ladwig 2015). But interference and dependency are hardly breaches of sovereignty in this case. Instead, they are consistent with the common good of those who comprise that subject as a national people having suffered some calamity. But a similar point can also be made without reference to the idea of sovereignty in the very different case of dependent children. After all, few would contest that parents caring for their children through their development into adults constitutes a case of arbitrary, dominating interference. Few would contest this given that positive interference is exercised non-arbitrarily in their best interest, as immature humans with decidedly limited capacities for sovereign self-determination.

As for the second criterion, non-domination can be secured through self-initiated accountability mechanisms that check the arbitrariness of the interference. These include public justification, public contestation, and retribution (Benton 2014). Here, the non-arbitrariness of interference may be justified through a combination of tracking common interests and holding open the permanent possibility of contestation on behalf of others. So, interference through foreign aid is subject to oversight by NGOs and IGOs, whose judgments are publicly contestable. Would-be interferers are held accountable for how they interfere by those who experience their interference as domination taking their grievances for adjudication in international courts. Or, regarding dependent children lacking developed powers of autonomy and self-determination, parental interference may still constitute non-domination to the extent it can be appropriately checked by publicly contestable child protection laws.

\subsection{The Species Good of Wild Boars}

The contestability of the interference with wild boars means little unless we can show that it promotes the 'common good' of the subject. How might we understand the impact of 
supplemental feeding on the common good of wild boars? 'The species norm' might be the closest approximation of the good presented so far (Rollin 1992; Nussbaum 2006). This is developed in response to errors necessarily associated with conceiving of the good at the individual biocentrist level and the ecosystemic level respectively. To exemplify this, Rolston III (1985) argues that, at the level of the individual organism, even reproduction may be unnecessary as it entails duress, risk, and energy expenditure. This would skew the argument heavily in favor of supplementary feeding as an immediate, short-term good for the hungry boar, but that is too simplistic. Conversely, if viewed ecocentrically, the common good of the boars might be the cessation, or gradual phasing out, of supplementary feeding to ensure that the population returns to the actual carrying capacity of the environment. But this would necessarily entail sacrificing individuals, which is difficult to reconcile with the common good of the wild boar species.

The species norm instead proceeds on a middle-ground and eschews the pitfalls of the biocentrist and ecocentrist perspectives respectively. It is a good that can be apprehended without the insider perspective of the organism (Rollin 1992). It can be identified by observing that certain activities constitutively contribute to their well-being as a species (Ladwig 2015). The anthropocentrism inherent to ascertaining the species norm of any non-human animal is counteracted to the extent that studies are grounded in close observation and an openness of perspective that can cultivate an understanding of their particular needs (Donovan 2006). Where wild boars are concerned, the species thrives when rooting, foraging, wallowing in dirt or against trees, feeding from diverse foods given their omnivore status and adaptability. Moreover, they are social creatures who synchronise birth and nursing behavior within matriarchal units. Mindful of this, what does the interference of supplemenary feeding do to these goods?

\subsection{Justifying Interference with the common good of boars}


Ways in which supplemental feeding would violate the species norm of boars and present a relation of domination include the following. The good of boars would be inhibited to the extent that supplementary feeding compromised their natural behaviour or frustrated their preferences for the abovementioned activities (Horta 2013). If feeding limited the range of things they could do and food sources from which they could forage, their options would be frustrated, and such restrictions are immoral (Bell 2006). For example, we will have interfered with their common good if the following effects were demonstrated. First, if supplementary feeding resulted in wild boars becoming less wary of humans in a way that might endanger them. Second, if we found that boars suffered any of the negative physiological or pathological effects of supplementary feeding purported in some research reports. These include stress from overcrowding at stations, the spread of diseases, or placing them at risk from lurking predators (Fischer; Stallknecht, Luttrell, Page; Dhondt and Converse 1997; Orams 2002; Dunkley and Cattet 2003).

Third, if a pathological adaptation to feeding stations contributed to a loss in capacity for natural foraging behavior. Ordinarily, the provision of supplementary feeding to an omnivore with a wide range of choices of feed would not impose high exit costs on the dependent subject (Lovett 2010). Exit costs pertain to the harms of deprivation associated with leaving the relation. As Wall (2001) asserts:

...submission to the arbitrary will of another does not really constitute being dominated by the other if one is perfectly free to walk away from the relationship whenever one wants without incurring any significant costs. (51)

Because of wild boars' opportunism and flexibility (Lindblom 2011), they could sustain themselves by alternating between their diverse natural food sources: leaves, bark, insects, 
earthworms, bird eggs, frogs, fish, roots, tubers, nuts, and a range of crops including maize, wheat, and sugar beets (Wilson 2004; Herrero, García-Serrano, Couto, Ortuño, Vicente and García-González 2006). The exit costs for wild boars from this feeding relation then are relatively low compared, for example, to koala bears who feed exclusively on Eucalyptus trees.

Nonetheless, we caution against appealing to the criterion of exit costs for determining domination, as we advocate abandoning the concept of sovereignty with respect to boars. Boars lack the necessary authority structures and critical faculties to exercise choice in walking away from the interference. Presented with easily accessible, high starch foods, they will automatically prefer these offerings. In the winter months, these sources will be even more attractive in comparison to the poor prospects elsewhere. Here, Lovett (2010) terms the presence of dismal choice (or in the boar's case, no choice) a case of agentless domination, in virtue of creating a relation of de facto dependence.

So far however, feeding has not resulted in any of the aforementioned side-effects. Boars have no natural predators that can take advantage of their vulnerablity, apart from humans. ${ }^{\text {ii }}$ To borrow Palmer's (2010) terminology, they are no less wild in the dispositional sense than before because they now feed at secluded forest stations. Indeed, they are a notoriously rare sight even by hunters' admissions. No sick boars have been uncovered, indeed the hardy stomach of the boar makes it apt to withstand the bacteria associated with feeding from the ground. There is only ever one pack of boars at the feeding station at any one time because boars are naturally shy and live in matriarchal units. They do not seem to mind crowding around their siblings for food or suffer density dependence (Magnusson 2010; Borowik, Curnlier and Jędrzejewska 2013). The one concern raised by wildlife managers in Sweden is that boars that regularly feed on sugar beets or unlawfully provided pastries risk sustaining cavities (Sveriges Radio, 2007) 
Finally, we must ask whether the presence of viable accountability mechanisms can render the interference of maintaining or stopping feeding non-arbitrary. On the one hand, justification refers to the tracking of common interests in the policy-making process, while accountability is an ex post mechanism that sanctions breaches of these interests. These two mechanisms pose few problems in the context of promoting the common interests of boars because they are administered by agents other than the hunters: for instance, the Swedish Environmental Protection Agency (SEPA), but also the criminal justice system in which boar feeding related offenses have been prosecuted in accordance with the hunting decree (Naturtidning 2004; Willsäter 2013). But, on the other hand, contestation requires self-initiation on the part of those who believe themselves to be the victims of dominating interference. This raises the altogether obvious problem that boars are not intentional agents who are capable of undertaking contestations addressed to the SEPA or criminal courts. To the extent they themselves are not intentional agents capable of self-initiation, the boars necessarily poses a problem of agent-less domination for anyone who would undertake contestations on their behalf in these fora. Nonetheless, we believe that it is reasonable to compensate for the absence of boars' intentionality and capability to address legal and political institutions by motivating a form of proxy contestation. This requires human proxies for boars to approximate and extrapolate from their perspectives in order to determine and promote their best interests when making contestations of current policy on their behalf. Donaldson and Kymlicka contend that such 'trust models' (Silvers and Francis 2005) in the form of ombudsmen, trustees, and advocates can exercise non-human animals' voice in institutional fora. We belive their reasoning is sound on this point. In Sweden, the SEPA rules on many hunting decisions, and nearly all wildlife management issues. But these rulings can be effectively contested by animal rights offices and animal welfare NGOs, possessing considerable power to ensure that the rights and interests of 
future generations and non-humans are heard as non-communicating co-citizens and liminals (Epstein and Darpö 2013).

\section{Objections to the Republican Framework}

In our introduction, we contended that Donaldson and Kymlicka's (2011) liberal political framework for RART points towards the republican standard that human interferences with nonhumans should be non-arbitrary and non-dominating. In the above section, we subsequently reapprehend interference in light of this standard. But this still leaves us with a range of difficulties accommodating non-human animals within the human parameters of political concepts, as characteristic of RART and the political turn. Consequently, we now critically engage some objections to using these concepts for understanding our relations and obligations to non-humans. We have already indicated problems with Donaldson and Kymlicka's appeal to the concept of sovereignty. We now turn to further complications regarding the boars' lack of moral powers and their lack of an authority structure. We also consider the problem of free will as it is understood in the animal context and some of the limitations of pursuing proxy contestation on their behalf.

First, Pettit's concept of domination as arbitrary interference necessarily involves overriding the moral powers of other humans for autonomous self-determination. It interferes with their ability to make revisable life-plans that are respectful one another's freedom and so become the captains of their own fate (Rawls 2005; Pettit 1996). But how does this apply to the boars? Do they possess functionally equivalent moral powers that could be overridden in such a way that they may be said to suffer domination? We have contended that wild boars indeed possess subjective goods and the capacity to comply with a certain degree with social cooperation defining their common species-life. However, they cannot conceptualize their future selves or formulate any revisable plan of life based on that conceptualization. Given the more limited form 
of moral powers they possess, boars cannot communicate to us their subjective goods in the manner of other humans capable of exercising the moral powers of self-determination in a system of just cooperation.

This creates a problem regarding the cognitive dimension to domination. Earlier, we argued that the animals in a nature park are dominated because of the guard's potential to interfere arbitrarily. But this example differs from the key example of domination in the republicanism literature - the relation of human master and human slave. Here, the slave is dominated by the master because of the former is able to anticipate that the latter can interfere arbitrarily, at any time (Pettit 1996). Indeed, it is this ability to conceptualize future interference that keeps the slave cowed and impedes his ability to use his moral powers to formulate a plan of life. But boars cannot anticipate arbitrary interference, and so prima facie it would seem that they cannot be dominated in this cognitivist sense. Hence, the application of the concept of domination to the boars calls for a departure from a condition of Pettit's theory: that the dominated must possess sovereign powers of self-determination, which can be overridden by a dominator. Consequently, we must appeal to domination in a suitably weakened form that relaxes Pettit's condition that the domination entails an ability to anticipate arbitrary interference.

Adjusted to agentless domination in Lovell's (2010) sense, we believe this weakened form is consistent with idea of domination as arbitrary interference in a range of marginal human cases. These include the severely cognitively disabled (Wong 2010), future generations of humans (Nolt 2011), children (Wilson 2001), in addition to some elders as subjects of domination. In these marginal human cases, interference may be arbitrary and dominating, but not because the cognitively disabled, future generations, and so on, are prevented from exercising their sovereign powers of self-determination by formulating revisable life-plans. All are cases of 
agentless or weak domination, in which the dominated lack these powers either entirely or in some substantial degree.

Previously, we acknowledged that the inability of boars to contest could be resolved by appeal to proxy contestation. Indeed, we now argue that this would proceed along the same lines as proxy contestation for future generations and other marginal cases. By analogy with boars, the latter cannot exercise their permanent possibility of contestation on account of not yet having been born, but they are not withheld the right to have this right exercised through proxies. But the analogy here is imperfect. Can boars be said to have the right to permanent possibility contestation through proxies? That is, can they be said to have such a right, given that they are complete creations who will never develop the cognitive capacities to contest by their own lights (Scruton 2000)? Unlike children and future generations, boars do not possess the potential to develop and become full moral members of society. In other words, they do not possess the potential for self-intitiation and self-determination. Not possessing this potential, they cannot be said to have a right to proxy contestation.

According to this objection, it is inappropriate to approximate similarities between marginal cases and animals. Indeed, it is tantamount to an anthropormpophism that attributes far too much 'humanity' to animals (Murdy 1998) and may be offensive to marginal humans. But this critique is difficult to substantiate. It is premised on a Cartesian blind that arbitrarily separes humans from non-human animals (Noske 2004). Even at cost of affording a higher moral status to severely cognitively disabled humans compared to animals that display cognitive capacities at times greater than those of marginal humans in certain selected tasks (Rogers and Kaplan 2004). There is now ample evidence not only of unique forms of animal intelligence, but of the present inability of humans to transcend human mediated systems of interpreting these expressions (Driessen 2014). Anthropocentrism thus challenges the analogy at a fundamental level (Noske 
1997), including the narrow ways in which cognition is currently understood and tested (Rogers and Kaplan 2004). We believe, then, that objections to this analogy on the basis that wild boars possess lower cognitive capacity as conventionally interpreted, or that as non-human animals they are fundamentally outside of the moral realm inhabited by marginal humans, are misguided.

Wild boars are on an equal moral footing with cognitively disabled humans insofar as they constitute moral patients to whom the rest of us are interrelated and to whom we owe obligations of care and respect. As moral patients, boars may be said to care about what happens to themselves without knowing that they do so. In simplest possible terms, they care about rolling in the mud, grubbing for roots, etc.-all those activities we equated with their good as a species. But they do not conceptualize these activities as for their good or formulate any life-plans on the basis of such higher-order conceptualizations (neither do marginal cases). At least, if they do, it is not something to which current cognition tests, however flawed, can testify. But this should not be a barrier and much less the cause for withholding of rights. Caring about their good without knowing it, their behaviors are purposive in the sense of aiming to fulfil those goods that they cannot, to our limited knowledge, conceptualize. Having purposes is the key to having the right to freedom (Gerwith 1978), even on the level of purposiveness exhibited by moral patients.

Indeed, the argument from marginal human cases demonstrates that we cannot easily deny moral patients the right to proxy contestation over their freedom. We certainly acknowledge that we are related to cognitively disabled humans in ways that create obligations towards them. We also acknowledge that it would be unacceptable to arbitrarily interfere with their enjoyments of goods they cannot conceptize as their goods on the basis of such cognitive or communicative deficits. Instead, we see it as morally encumbent on us to identify those goods appropriate to their range of characteristic purposive activites and to modulate our behaviors in relationship to them, according to our determination of their good. Indeed, for us to arbitrarily interfere with their 
purposive activities in pursuit of goods they can neither articulate nor communicate to us would surely amount to domination, albeit in the weakened form we identified above.

Consequently, we now say that domination in the weak form consists of arbitrary interference not with the self-chosen life-plans of rational agents with capacities for selfdetermination, but rather arbitrary interference with the good of any creature with whom we are interrelated. This is domination in the weak form consisting in arbitrary interference with a creature's good, as identified by virtue of careful observation of its characteristic set of purposive behaviours (Gudorf 2010). In the case of boars, this means that careful observation and identification of their species-good becomes the basis of proxy contestations of arbitrary or dominating interference. Such proxy contestations thus compensate for their inability to articulate their own good and to make use of this communicatively as the basis of self-intitiated contestations.

It might still be objected, though, that the boars cannot contest how their good is represented in proxy contestations. This much is certainly true. As representations of the boars' good, proxy contestations would have to be understood on the model of discursive representative claim-making (Saward 2006). Here, proxies would claim to represent the boars' good by depicting it in this or that way. For instance, they may depict the boars' good as consisting in wallowing in mud and grubbing for roots free from the arbitrary interfere of humans who would render them de facto dependent on feeding stations. The virtue of this discursive model of representation as claim-making is that it dispenses with the need to conceive of representation in terms of elections and voting - activities in which boars obviously cannot participate (Smith 2012; Driessen 2014). Indeed, if the good of boars is to be represented by proxies, then it has to be on this discursive model of representation. 
But discursive representations are legitimate only to the extent that they are contestable and those purportedly represented by a claim-maker can either accept or reject how they are represented. Claims to represent the good of the boars necessarily fail to satisfy this legimitating condition of discursive representation. To this extent, claims made by proxies to represent the good of boars would have to be reconceived so as to accommodate the weak form of domination. What would that mean? Claims to represent the good of boars should be acknowleded as legitimate, even though the represented - the boars — cannot contest how they are represented by the claim-makers who undertake proxy contestations on their behalf. This would not be problematic if the good of boars in relation to humans - hunters, state regulators, or animal rights advocates - could be treated as uncontroversial. But that is obviously not so.

Indeed, their good could be represented in other ways by other human claim-makers with different political agendas. Hunters might discursively represent the boars' good as a plentiful food supply in the summer months with the possibility of a clear kill relieving them of the agonies of slow starvation through the winter months. Who, then, is to say which representative claim is more representative of the boars' good? That of the proxies claiming to represent the boars' good through contestatons of supplementary feeding practices, or that of the hunters claiming to represent the boars' good through advocacy of such practices? The only uncontroversial answer to this question is that it cannot be a boar, for all its cognitive capacities that have yet to be revealed. But neither should it be any particular human. Rather, the legitimation of claims to represent the boars must be a function of open public deliberation among a pluralism of human claim-makers, boar-proxies, hunters, farmers, regulators, ecologists and wildlife-managers, and so on. In the language of deliberative democracy familiar from the work of Habermas (1985), legitimacy is the outcome of a deliberative process that includes the 
perspectives of all actors who are potentially affected by a public decision. To this extent, legitimacy is the outcome of the unforced force of the better argument.

Obviously, the boars themselves are affected by the resulting decision, and they are likely to be affected in ways that are more fundamental than hunters, farmers, and so on. After all, depending on the decision, they could get shot or they could lose a welcome feeding source. But the legitimacy of a decision is not forthcoming in any other way. A public decision cannot be said to be delegitimized because it is not contested by those whose good has been represented in a particular way but who cannot themselves contest this representation. Especially not when claimmakers and those they claim discursively to represent are already interrelated across species lines. Decisions have to be reached and so their legitimation must depend on the robust characters of the deliberative process of examining different kinds of representations of the boar's good and assessing their plausibility for satisfying the standard on non-arbitrary interference in light of multiple factors. This would include examination of the motivations of different kinds of claimmakers for self-interested biases in their representations of the boars' good and a critical survey of the scientific literature on the physiological, pathological, ethological, and ecological characteristics of boars and the projected impacts of alternative kinds of interferences. But we also contend that policy needs to be validated discursively in moral concerns (Habermas 1996).

To render these recommendations concrete, the wild boar management issue in Sweden as well as elsewhere requires appropriate fora at institutional levels. Consistent with our previous work (von Essen and Allen 2015), we advocate the creation of deliberative mini-publics targeting affected actors with interests in representing the boar and challenging them to defend their representation in light of expert and scientific information. We contend the potential for a policy solution held as legitimate by all is relatively high, given that the wild boar represents a new game species without a management tradition which might otherwise challenge consensus. 
Unlike the case for more controversial species, such as wolves, practices and ethics toward the boar are being continuously negotiated by a wide range of actors, primarily across media (Larsson 2014; Olsson 2014).

We argue a RART-informed political discussion in mini-publics that centres on the place of boars in the landscape and our interspecies relations represents a far more constructive approach than contesting claims made in media. Moreover, mini-publics of human claim-makers not only subjects alternative representations of the boar's good to critical scrutiny, but also the self-representation of hunters as themselves the victims of arbitrary interferences by state regulation of their interactions with boars. Indeed, hunters frequently present themselves as the victims of domination insofar as hunting regulations may impede their ability to pursue life-plans that include taking the lives of non-humans for sport. Such self-representations would be problematized just as much as the other-regarding representations offered in public deliberation by boar-proxies.

\section{Conclusion: A Republican Framework}

Where does this now leave us with respect to a republican framework for relational animal ethics? We began by noting Donaldson and Kymlicka's political approach to RART already pointed in a republican direction. It pointed to republicanism insofar as it explicitly problematized liberal freedom as non-interference in abolitionist and hand-off approaches to animal rights, instead favouring the integration of negative rights and positive relations. But we also signalled certain conceptual weakness in their approach to RART, especially with respect to their use of the concepts of sovereignty and representation. Indeed, we have reinterpreted the political turn in light of a republican conception of the obligation to ensure that human interferences with non-humans satisfy a standard of non-arbitrariness or non-domination. 
To follow through on this reinterpretation, however, we have argued for a weakening of the concept of domination in republican theory. In particular, it must be weakened to accommodate agentless domination in which arbitrary interference cannot be understood as overriding any sovereign powers of self-determination. Agentless domination, though, encounters the problem that boars as dominated cannot undertake contestations of their own relations of domination with humans. To compensate for this cognitive and communicative deficit on their part, we appealed to proxy contestations in which human proxies purport to represent the good of the boars. Here, we attempted to clarify, where Donaldson and Kymlicka do not, the nature of such representation by appeal to the idea of contestable representative claim-making. But, again, discursive representative claim-making is not contestable by the boars as the represented. Consequently, the legitimacy of interferences depends upon a discourse of human agents with competing interests in representing the good of boars in publicly contestable ways. Indeed, such a discourse may be facilitated by the creation of institutional fora in which differently-interested representative claim-makers are challenged to defend their claims regarding the good of boars in light of empirical studies and information.

All in all, then, we claim to have provided a viable republican framework for RART that expands on the work begun by Donaldson and Kymlicka and resolves the weakness in their approach with respect to sovereignty and representation. Contrary to them, we have argued that sovereignty is not a useful concept for RART and that it should be dropped in light of the problem of agentless domination. RART cannot, however, do without a concept of representation, but this has to be adapted to the same problem of domination. This is accomplished by discursive representation, provided that claims to represent the goods of nonhumans can be robustly contested in appropriate institutional fora challenging the biases and epistemic limitations of claim-makers. Our argument has not been concerned with advancing any 
particular proposal with respect to continuing, discontinuing or regulating feeding stations to any greater or lesser extent. Instead, it has been concerned only with advancing a suitable political framework of legitimation for reaching justifiable public decisions regarding the latter range of options. Any such decisions with respect to what constitutes non-arbitrary interference tracking the good of boars and establishing non-dominating inter-species relations with them must survive robust deliberative testing across the diverse perspectives of interested claim-makers and experts.

Erica von Essen is a $\mathrm{Ph}$. D researcher with the Environmental Communication Division at the Swedish University of Agricultural Sciences. Her topics include contestation and resistance in the context of wildlife and environmental issues; political animal theory and deliberative democracy. E-mail: erica.von.essen@slu.se

Michael Allen is an associate professor of social, political, and legal philosophy at East Tennessee State University. He has published in Criminal Law and Philosophy, Contemporary Political Philosophy, Theoria, and Philosophy and Social Criticism among numerous other journals. E-mail: allenmp@etsu.edu

\section{References}

Allen, Michael P. 2011. "Is Liberty Bad for Your Health? Towards a Moderate View of the Robust Coequality of Liberty and Health." Public Health Ethics 4(3): 260-68

Apollonio, Mark; Andersen, Reidar; and Putman, Rory. 2010. "Present status and future challenges for European ungulate management " In European Ungulates and their Management in the 21st Century, edited by M. Apollonio, R. Andersen and R. Putman, 578-604. Cambridge, UK: Cambridge University Press.

Bateson, Patrick. 1989. "Does evolutionary biology contribute to ethics?" Biology and Philosophy 4(3): 287-301

Bell, Daniel. 2006. "Justice for Migrant Workers? The Case of Migrant Domestic Workers in East Asia." In Beyond Liberal Democracy: Political Thinking in an East Asian Context, edited by D. Bell, 281-322. Princeton, NJ: Princeton University Press.

Benton, Meghan. 2011. A Theory of Denizenship. Doctoral Dissertation. Department for Political Science, University College London. 
2014. "The problem of denizenship: a non-domination framework." Critical Review of International Social and Political Philosophy 17(1): 49-69

Bieber, Claudia and Ruf, Thomas. 2005. "Population Dynamics in Wild Boar Sus Scrofa:

Ecology, Elasticity of Growth Rate and Implications for the Management of Pulsed

Resource Consumers." Journal of Applied Ecology 42 (6):1203-13

Borowik, Tomasz; Cornulier, Thomas; and Jędrzejewska, Bogumila. 2013. "Environmental

Factors Shaping Ungulate Abundances in Poland." Acta Theriologica 58(4):403-13

Brittingham, Margaret. C. and Temple, Stanley. 1988. "Impacts of Supplemental Feeding on

Survival Rates of Black-Capped Chickadees." Ecology 69(3): 581-89

1992. "Does Winter Bird Feeding Promote Dependency?" Journal of Field Ornithology

63: 190-94

Burgess-Jackson, Keith. 1998. "Doing Right by Our Animal Companions." The Journal of Ethics 2: 159-85

Cahoone, Lawrence. 2009. "Hunting as a Moral Good." Environmental Values 18(1): 67-89

Chinery, Michael. 2004. Attracting Wildlife to your Garden. London, UK: Collins.

Clement, Grace. 2003. "The Ethic of Care and the Problem of Wild Animals." Between the Species 13(3): 1-12

Cochrane, Alastair. 2013. "Cosmozoopolis: The Case Against Group-Differentiated Animal Rights." Law, Ethics and Philosophy 1: 127-41

Curtin, Deane. 1991. "Toward an Ecological Ethic of Care." Hypatia 1: 60-74

Donaldson, Sue and Kymlicka, Will. 2011. Zoopolis Oxford, UK: Oxford University Press. 2015. "Interspecies Politics: Reply to Hinchcliffe and Ladwig." Journal of Political Philosophy 23(3): 321-44

Donovan, Josephine. 2006. "Feminism and the Treatment of Animals: From Care to Dialogue." Signs 31(2): 305-29

Driessen, Clemens. 2014. "Animal Deliberation." In Political Animals and Animal Politics, edited by M.L.J. Wissenburg and D. Schlosberg, 90-104. London: Palgrave Macmillan UK

Dunkley, L. and Cattet, M. 2003. A Comprehensive Review of the Ecological and Human Social Effects of Artificial Feeding and Baiting of Wildlife. Saskatchewan, Saskatoon: Canadian Cooperative Wildlife Health Center. 
Eckersley, Robyn. 1999. "The Discourse Ethic and the Problem of Representing Nnature." Environmental Politics 8(2): 24-49

Epstein, Yaffa and Darpö, Jan. 2013. "The Wild Has No Words: Environmental NGOs Empowered to Speak for Protected Species as Swedish Courts Apply EU and International Environmental Law." European Environmental \& Planning Law 10(3): $250-61$

Everett, Jennifer. 2001. "Environmental Ethics, Animal Welfarism, and the Problem of Predation: A Bambi Lover's Respect for Nature." Ethics and the Environment 6(1): 42-67

Fischer, John R.; Stallknecht, David E.; Luttrell, Page; Dhondt, Andre; and Converse, Kathryn. 1997. "Mycoplasmal Conjunctivitis in Wild Songbirds: The Spread of a New Contagious Disease in a Mobile Host Population." Emerging Infectious Diseases 3(1): 69-72

Friedman, Marilyn. 2008. "Pettit's Civic Republicanism and Male Domination." In Republicanism and Political Theory, edited by Cecil Laborde and John Maynor, 246-268 Oxford: Wiley-Blackwell

Gadolin, Marie. 2014. Fortsatt hög acceptans för jakt. http://svenskjakt.se/Start/Nyheter/2014/08/fortsatt-hog-acceptans-for-jakt/. Accessed on March 5, 2015

Geisser, Hannes and Reyer, Heinz-Ulrich. 2004. "Efficacy of Hunting, Feeding, and Fencing to Reduce Crop Damage by Wild Boars." The Journal of Wildlife Management 68(4): 93946

Gerwith, Alan. 1978. Reason and Morality. Chicago, IL: The University of Chicago Press. Green, Ronda and Higginbottom, Karen. 2000. "The Effects of Non-consumptive Wildlife Tourism on Free-ranging Wildlife: A Review." Pacific Conservation Biology 6(3): 18397

Gudorf, Christine. 2010. A Casebook in Environmental Ethics. Washington, DC: Georgetown University Press.

Habermas, Jürgen. 1996. Between Facts and Norms: Contributions to a Discourse Theory of Law and Democracy. Translated by W. Rehg. Cambridge, MA: MIT Press.

Hampton, Jordan O.; Spencer, Peter; B.S., Alpers; Deryn L., Twigg; Laurie, Woolnough, Andrew; Doust, Jeff; Higgs, Tony; and Pluske, John. 2004. "Molecular Techniques, 
Wildlife Management and the Importance of Genetic Population Structure and Dispersal: A Case Study With Feral Pigs." Journal of Applied Ecology 41(4): 735-43

Henderson, Katherine. 2009. Relational Approaches to Animal Ethics and the Intuition of Differential Obligations. Victoria, BC: University of Victoria.

Herrero, Juan; García-Serrano, Alicia; Couto, Sergio; Ortuño, Vicente; and García-González, Ricardo. 2006. "Diet of Wild Boar Sus scrofa L. and Crop Damage in an Intensive Agroecosystem." European Journal of Wildlife Research 52(4): 245-50

Hettinger, Ned. 1994. "Valuing Predation in Rolston's Environmental Ethics: Bambi Lovers

Versus Tree Huggers." Environmental Ethics 16(1): 3-20

Hinchcliffe, Christopher. 2015. "Animals and the Limits of Citizenship: Zoopolis and the Concept of Citizenship." Journal of Political Philosophy 23(3): 302-20

Horta, Oscar. 2013. "Zoopolis, Intervention, and the State of Nature." Lae, Ethics and Philosophy (2): $113-125$

Johansson, Lisa. 2005. Vildsvinen tär på grannsämjan. http://www.sydsvenskan.se/sverige/vildsvinen-tar-pa-grannsamjan/. Accessed on March 5 2015

Jones, Darryl. 2011. "An Appetite for Connection: Why We Need to Understand the Effect and Value of Feeding Wild Birds." Ети 111(2): i-vii and Reynolds, James. 2008. "Feeding Birds in Our Towns and Cities: A Global Research Opportunity." Journal of Avian Biology 39(3): 265-71

Kellert, Stephen. 1997. Kinship to Mastery: Biophilia in Human Evolution and Development. Washington, DC: Island Press.

Kerasote, Ted. 1994. Bloodties. Nature, Culture, and the Hunt. New York: Kodansha International.

Keuling, Oliver; Stier, Norman; and Roth, Mechthild. 2009. "Commuting, Shifting or Remaining?: Different Spatial Utilisation Patterns of Wild Boar Sus scrofa L. in Forest and Field Crops During Summer." Mammalian Biology - Zeitschrift für Säugetierkunde. 74(2): 145-52

Ladwig, Bernd. 2015. "Against Wild Animal Sovereignty: An Interest-based Critique of Zoopolis." Journal of Political Philosophy 23(3): 282-301 
Larsson, Håkan. 2014. Så kan vi reglera vildsvinsstammen.

http://www.aftonbladet.se/debatt/debattamnen/politik/article19177732.ab Accessed on March 52015

Leaper, R.; Massei, G.; Gorman, M.L.; and Aspinall, R. 1999. "The feasibility of reintroducing Wild Boar (Sus scrofa) to Scotland." Mammal Review 29(4): 239-58

Lemel, Jonas and Truve, Johan. 1999. Populationstillväxt, dynamik och spridning hos vildsvinet, Sus scrofa, i mellersta Sverige. Swedish Environmental Protection Agency. Uppsala Lindblom, Sofie. 2011. Distribution of Wild Boar (Sus scrofa) Damage and Harvest Lloss in Crop Fields. Department of Ecology, Lund University, Lund

Littin, K.E. and Mellor, Dominic. 2005. "Strategic Animal Welfare Issues: Ethical and Animal Welfare Issues Arising From the Killing of Wildlife for Disease Control and Environmental Reasons." Revue scientifique et technique 24(2): 767-82

Loftin, Robert. 1984. "The Morality of Hunting." Environmental Ethics 6: 241-250

Lovett, Frank. 2010. A General Theory of Domination and Justice,. Oxford, UK: Oxford University Press.

Lukasik, Victoria and Alexander, Shelley. 2011. "Human-Coyote Interactions in Calgary, Alberta." Human Dimensions of Wildlife 16(2): 114-27.

Luke, Bryan. 1997. "A Critical Analysis of Hunters' Ethics." Environmental Ethics 19(1): 25-44 Mackenzie, Catriona and Stoljar, Natalie. 2000. Relational Autonomy: Feminist Perspectives on Autonomy, Agency and the Social Self. Oxford, UK: Oxford University Press.

MacKinnon, Catherine. 2005. Women's Lives, Men's Laws. Cambridge, MA: Harvard University Press.

Magnusson, Madelene. 2010. Population and Management Models for the Swedish Wild Boar (Sus scrofa). Biology and Social Science, Swedish University of Agricultural Sciences. Grimsö

Massei, Giovanna; Coats, Julia; Quy, Roger; Storer, Kate; and Cowan, Dave. P. 2010. "The BoarOperated-System: A Novel Method to Deliver Baits to Wild Pigs." The Journal of Wildlife Management 74(2): 333-36

Midgley, Mary. 1983. Animals and Why They Matter. Athens, GA: University of Georgia Press. Moriarty, P. and Woods, M. 1997. "Hunting (not equal to) Predation." Environmental Ethics 19(4): 391-404. 
Murdy, William. H. 1998. "Anthropocentrism: A Modern Version." In Environmental Ethics:

Divergence and Convergence, edited by R. Botzler and S. Armstrong, 1168-1172 Boston, MA: McGraw Hill.

Naturtidning, L. 2004. Bonde dömdes för jaktbrott vid vildsvinsjakt.

http://www.atl.nu/lantbruk/bonde-domdes-jaktbrott-vid-vildsvinsjakt. Accessed on March 1 st 2015

Noddings, Nell. 1984. Caring, a Feminine Approach to Ethics and Moral Education. Berkeley, CA: University of California Press.

Nolt, John. 2011. "Nonanthropocentric Climate Ethics." Wiley Interdisciplinary Reviews: Climate Change 2(5): 701-11

Noske, Barbara. 1997. "Speciesism, Anthropocentrism, and Non-Western Cultures." Anthrozoös 10(4): 183-90

2004. "Two Movements and Human-Animal Continuity: Positions, Assumptions, Contradictions." Animal Liberation Philosophy and Policy Journal 2(1): PAGES? No page numbers

Nussbaum, Martha. 2006. Frontiers of Justice: Disability, Nationality, Species Membership. Cambridge, MA: Harvard University Press.

Olsson, Camilla. 2014. Vill tillåta vildsvinsjakt med automatvapen. http://www.lantbruk.com/lantbruk/vill-tillata-vildsvinsjakt-med-automatvapen. Accessed on March 1st 2015

Orams, Mark. B. 2002. "Feeding Wildlife as a Tourism Attraction: A Review of Issues and Impacts." Tourism Management 23(3): 281-93.

Palmer, Claire. 2012. "What (If Anything) Do We Owe Wild Animals?" Between the Species 16(1): 4 .

Parkes, John. P.; Ramsey, David; S.L., Macdonald; Norman., Walker; Kelvin, McKnight; Sean, Cohen; Brian. S.; and Morrison, Scott A. 2010. "Rapid Eradication of Feral Pigs (Sus scrofa) from Santa Cruz Island, California." Biological Conservation 143(3): 634-41.

Peterson, M. Nils. 2004. "An Approach for Demonstrating the Social Legitimacy of Hunting." Wildlife Society Bulletin 32(2): 310-21

Pettit, Philip. 1996. "Freedom as Antipower." Ethics 106(3): 576-604 
2001. A Theory of Freedom: From the Psychology to the Politics of Agency. Cambridge, UK: Polity Press.

Regan, Tom. 1983. The Case for Animal Rights. Berkeley, CA.: University of California.

Rogers, Lesley and Kaplan, Gisela. 2004. "All Animals Are Not Equal: The Interface between

Scientific Knowledge and Legislation for Animal Rights." In Animal Rights: Current

Debates and New Directions, edited by C. Sunstein, R and M. Nussbaum, 175-201.

Oxford, UK: Oxford University Press.

Rollin, Bernard. E. 1992. Animals Rights and Human Morality, 3rd edition. Amherst, NY:

Prometheus Books.

Rolston III, Holmes. 1985. "Duties to Endangered Species." BioScience 35: 718-26

Sveriges Radio, 2007. Vildsvin får hål i tänderna Sveriges Radio.

Sagoff, Mark. 1984. "Animal Liberation and Environmental Ethics: Bad Marriage, Quick

Divorce." Osgoode Hall Law Journal 22(2): 297-307.

Samuel, David. 1999. Know Hunting: Truths, Lies and Myths. Cheat Lake, WV: Know Hunting Publications.

Saward, Michael. 2006. "The Representative Claim." Contemporary Political Theory 5(3): 297_ 318

Scruton, Roger. 2000. Animal Rights and Wrong. London: Claridge Press.

Silvers, Anita and Francis, Leslie. 2005. "Justice through Trust: Disability and the 'Outlier Problem; in Social Contract Theory." Ethics 116(1): 40-76.

Smith, Kimberly. 2012. Governing Animals: Animal Welfare and the Liberal State. Oxford, UK: Oxford University Press.

Svendsen Bjørkdahl, Kristian. 2005. The Wild Ember Within: A Study of the Hunting Ethos in Norway and the USA. Centre for Development and the Environment, University of Oslo, Blindern.

Taylor, Paul. 1992. "The Ethics of Respect for Nature." In The Environmental Perspective, edited by C. Hargrove, 95-120. Albany, NY: University of New York Press.

Ucarli, Yasin. 2011. "Effects of Wild Boar (Sus scrofa) on Farming Activities: A case Study of Turkey." African Journal of Biotechnology 10(44): 8823-28. 
Wadiwel, Dinesh Joseph. 2013. "Zoopolis: Challenging our Conceptualisation of Political Sovereignty Through Animal Sovereignties." Dialogue: Canadian Philosophical Review/Revue canadienne de philosophie 52(4): 749-58

Wall, Steven. 2001. "Freedom, Interference, and Domination." Political Studies 49(2): 216-30.

Willsäter, Lotta. 2013. Lockbetor blir polissak. http://www.corren.se/nyheter/lockbetor-blirpolissak-6632526.aspx Accessed on February 202015

Wilson, Charles J. 2004. "Rooting Damage to Farmland in Dorset, Southern England, Caused by Feral Wild Boar Sus scrofa." Mammal Review 34(4): 331-35.

Wilson, Scott. 2001. "Carruthers and the Argument from Marginal Cases." Journal of Applied Philosophy 18(2): 135-47.

von Essen, Erica, and Allen, Michael P. 2015. "Reconsidering Illegal Hunting as a Crime of Dissent: Implication for Justice and Deliberative Uptake " Criminal Law \& Philosophy VOLUME?: 1-16.

Wong, Sophia Isako. 2010. "Duties of Justice to Citizens with Cognitive Disabilities." In Cognitive Disability and Its Challenge to Moral Philosophy EDITOR?, 127-46. Hoboken, NJ: Wiley-Blackwell.

Wood Jr., Forrest. 1996. The Delights and Dilemmas of Hunting: The Hunting Versus AntiHunting Debate. Lanham, MD: University Press of America.

\footnotetext{
${ }^{\mathrm{i}}$ Apart from a maternal line orientation

${ }^{\text {ii }}$ A future concern may be that where boar and wolf populations coincide, piglets might be of some risk. This is however not substantiated by any research.
} 